\title{
A pilot study of methodology for the development of farmland habitat reports for sustainability assessments
}

\author{
J.A. Finn ${ }^{1 \dagger}$, P. Moran ${ }^{2}$ \\ ${ }^{1}$ Teagasc, Environment Research Centre, Johnstown Castle, Wexford, Ireland \\ ${ }^{2}$ Forest, Environmental Research and Services Ltd., Sillogue, Kilberry, Navan, Co. Meath, Ireland
}

Abstract

The inclusion of farm maps of habitat features is becoming an urgent requirement for assessments of farm-scale sustainability and for compliance or benchmarking with national and international sustainability certification and accreditation schemes. Traditional methods of habitat assessment rely strongly on field-based surveys, which are logistically demanding and relatively costly. We describe and investigate a process that relies on information technology to develop a scalable method that can be applied across multiple farms to reduce the significant logistical challenges and financial costs of traditional habitat surveys. A key impediment to the routine development of farm habitat maps is the lack of information on the type of habitats that occur on a land parcel. Within a pilot project comprising 187 farms, we developed and implemented a process for creating farm habitat reports and investigate the accuracy of visual interpretation of satellite imagery by an ecologist aiming to identify habitat types. We generated customised farm reports that included a colour-coded farm habitat map and habitat information (type, area, relative wildlife importance). Visual assessment of satellite imagery achieved an overall accuracy of $96 \%$ in its ability to discriminate between land parcels with habitats categorised by this study as being of either high or low nature conservation value. Assessment of satellite imagery achieved an overall accuracy of $90 \%$ in its ability to discriminate among Fossitt level II habitat classes, and an overall accuracy of $81 \%$ when using individual habitat classes (Fossitt level III). There was, however, considerable variation in the accuracy associated with individual habitat classes. We conclude that this methodology based on satellite imagery is sufficiently accurate to be used for the incorporation of farmland habitats into farm-scale sustainability assurance, but should, at most, use Fossitt level II habitat classes. We discuss future challenges and opportunities for the development of farm habitat maps and plans for their use in sustainability certification schemes.

Keywords

Biodiversity $\bullet$ farmland wildlife $\bullet$ GIS $\bullet$ habitat $\cdot$ mapping $\bullet$ sustainability

\section{Introduction}

Sustainable agricultural practices are a high priority policy goal for society. Although there is a great variety of approaches for the measurement and assessment of sustainability, the environmental dimension of sustainability universally includes at least soil, air, water and biodiversity (Hayati, 2017; United Nations, 2018). In response to a combination of policy goals, consumer pressure and a need to maintain ecosystem services that underpin agricultural production, agri-food industries are increasingly committed to attaining sustainable farming systems. The formal assessment, certification and accreditation of agricultural sustainability is an important performance standard and marketing opportunity. The inclusion of biodiversity in sustainability assessment and certification seems to lag behind other aspects (e.g., soil, air and water) (Addison et al., 2018). This is a significant weakness, given the importance of biodiversity and its priority in underpinning sustainability goals. In addition, the inability to accurately assess impacts on wildlife species and habitats can have a high potential for reputational damage to an associated product or business (e.g., Treves \& Jones, 2010; Parguel et al., 2011; Dempsey, 2013; Boiral, 2016; Barbier et al., 2018).

Globally, agri-food companies are undertaking sustainability assessments for compliance or benchmarking with international 
accreditation schemes. There are several examples of accreditation schemes. To focus on one example, the Sustainability Assessment Initiative (SAI) Platform is a global initiative (of considerable interest to several agri-food business in Ireland), and includes several biodiversity criteria (essential, basic and advanced) in its Farm Sustainability Assessment (FSA) tool (www.saiplatform.org). Those biodiversity criteria (from SAI Platform) are as follows:

Basic: Have you assessed biodiversity and identified priority actions to preserve biodiversity on your farm?

- Identification of on-farm rare and endangered species (plant and animal).

- Identification of priority actions that promote biodiversity on farm.

- Take part in a biodiversity plan at landscape level if available and practical.

Advanced: Do you have a biodiversity plan for your farm to maintain or improve biodiversity?

- A map of areas or features important to biodiversity on and around the farm.

- Details of how provision is made for wildlife habitats and food sources through hedges, field margins, extensive pasture, etc.

- Measures to avoid degradation and deforestation of high conservation value $(\mathrm{HCV})$ areas or other ecologically sensitive areas.

- Assessment of possible disruption of biological corridors because of farm activities and if required, based on the assessment mitigation measures.

Essential: Have you left all primary forest, wetland, peatland and protected grassland or other native eco-systems in its original condition within the last 5 years?

- Includes ensuring that no practices were used that could weaken or destroy primary forest, wetland, peatland, grassland or other native eco-systems.

Basic: If you have deforested secondary forest or cleared grassland, did you ensure that you have acted legally and that you have the right permits?

Advanced: Do you practice habitat restoration and do you compensate for areas on your farm that have been prone to habitat/biodiversity loss?

Basic: If you work next to or in protected areas, do you work with legal permits and ensure that your activities do not harm the ecosystem?

- Protected areas include national parks, wildlife refuges, biological corridors, forestry reserves, buffer zones or other public or private biological conservation areas.

- If you are located next to such protected areas it is recommended to establish and maintain buffer zones.

(from the SAI Platform)
Across the agri-food industry, many sustainability assessments require that farmland wildlife habitats are inventoried and mapped in some way. Because assessments are usually for individual farms, wildlife habitat inventories can be achieved by indicating the spatial location of farmland habitats on a map. Traditionally, the creation of farm habitat maps required a field visit, which is time-consuming and costly and represents a significant disincentive to conduct a farm habitat plan across large numbers of farms.

Here, we investigated the use of satellite imagery to identify farm habitats without the need to visit individual farms, with the aim of developing more cost-effective and customised farm habitat plans. We also aimed to develop a process to improve the assessment, documentation and communication of farm wildlife habitats and their management. This could be variously used by farmers to prioritise their wildlife conservation activities and by agri-food companies to provide evidence of their assessment of farmland habitats as part of sustainability certification. Specific objectives of this study included:

1. Conduct a pilot study to collect farm habitat information, and develop a process to collate this information and produce customised farm habitat reports,

2. Measurement of the accuracy of satellite imagery to discriminate between habitats categorised as being of either high or low nature conservation value (level II in Fossitt, 2000), by comparison with field data,

3. Measurement of the accuracy of satellite imagery to identify habitats (level III in Fossitt, 2000),

4. Investigation of the use of photographs to improve the accuracy of habitat identification.

\section{Materials and methods}

Farmers were contacted by SMS with an invitation to be involved in the project and give permission to use their Land Parcel Identification System (LPIS) data to identify their farm boundary and have a farm habitat plan prepared for their farm. None of the other LPIS information was available to us. Note that participation was voluntary, and the selection of farming systems was not intended to be nationally representative; instead, we aimed to include a range of farming systems that varied to include extensively managed high nature value farming systems as well as intensively managed dairy, beef and cereal systems (e.g., see Matin et al., 2016, 2020). Approximately $20 \%$ of the farms were extensively managed livestock farms of high nature value; about $15 \%$ were cereal farms and the remainder were a combination of more intensively managed dairy and beef farms. The majority of participants were located in counties Cork, Galway, Kerry, Kildare, Kilkenny, Meath, Tipperary and Wexford. 
A total of 187 individual farms participated in the project. Through interpretation of satellite imagery alone, an ecologist with experience of this methodology recorded discrete habitats on the farms as polygons/lines in accordance with the habitat mapping guidelines as outlined in Smith et al. (2011). The imagery utilised for identifying habitats was the Economic and Social Research Institute (ESRI0 Digital Globe Satellite Imagery from 2013. (More up-to-date satellite imagery is now available from Bing, which is regularly updated. It is recommended that Bing Maps or Google Maps be utilised in future analysis.)

In an independent task, each of the 187 farms was visited in 2016 and their habitats mapped by ecologists (in accordance with the habitat mapping guidelines as outlined in Smith et al. [2011]), none of whom had conducted the habitat assessment based on satellite imagery (and did not have access to the results of the habitat assessment based on satellite imagery). Each farm was surveyed by walk-over survey, with all habitats occurring within the farm boundary identified according to Fossitt (2000). The habitat data were entered into a geographic information system (GIS) database, created in ArcGIS 10.2 using standard methodology according to the guidelines as presented in Smith et al. (2011) (which were utilised for the purposes of both image analysis and field surveys), into which were entered new features (polygon or line) associated with each of the habitat types according to Fossitt (2000).

The following information was entered on a database for each farm:

- a colour-coded image of a farm habitat map (based on the field survey) with a legend linking the colours to habitat types;

- a list of habitats for each individual farm and their estimated area and an indication of their relative wildlife conservation value (see column titled Relative Wildlife Importance in Appendix 1 for an example). The assessment of relative wildlife value is quite a coarse gradation, it was conducted by the authors, and is based on the conservation value of the vegetation associated with each of the habitats in Fossitt (2000) on a 6-point scale through low, low-tomedium, medium, medium-high, high and very high;

- for each habitat, a list of generic recommendations for practices to promote wildlife conservation (see Appendix 1 for an example).

In addition, for each habitat, some short generic notes were inserted (through the database) as general information on the ecological importance of habitats and general management practices to maintain/enhance the ecological value of habitats (see Appendix 1 for an example). This information facilitated the generation of customised farm reports that included habitat information for only the habitats

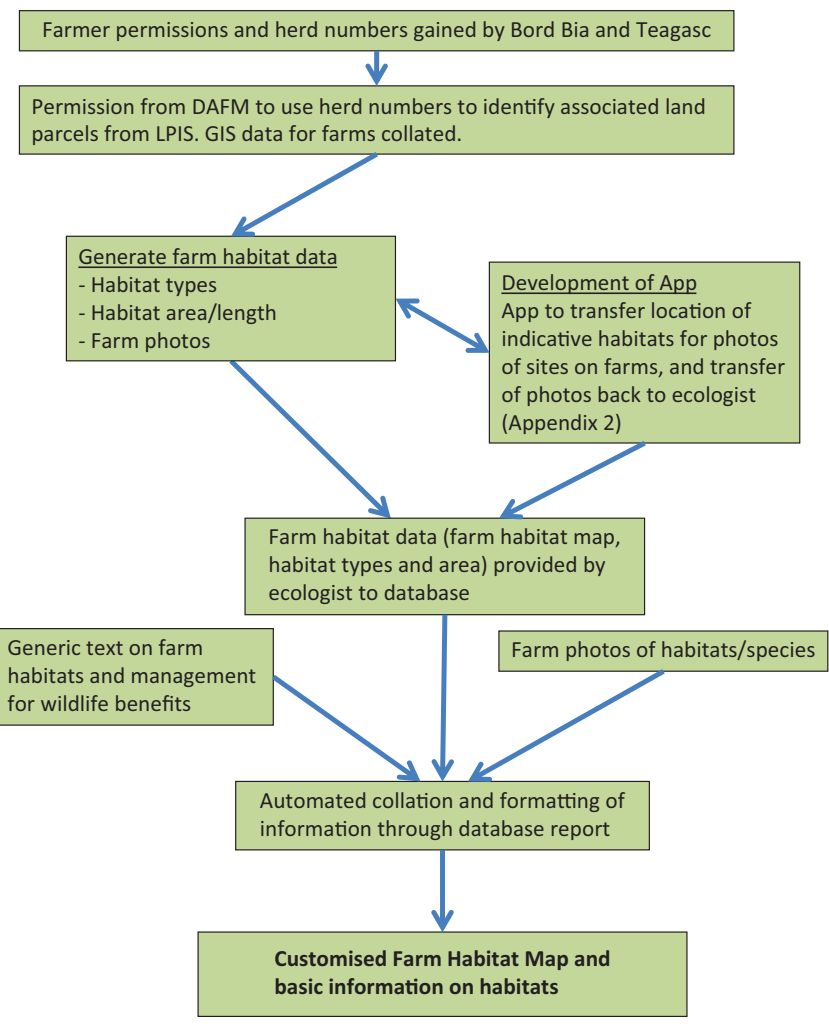

Figure 1. Overview of the various work steps in constructing the customised farm habitat reports.

that occurred on an individual farm (for an overview of the process, see Figure 1).

Comparison of the habitat data from the ground-truthing (farm visit) with the habitat data (for Fossitt levels II and III) from the interpretation of satellite imagery alone allowed us to assess the accuracy of the latter. The habitat identification through satellite imagery was conducted independently of the habitat assessment through field visits. The accuracy of the habitat identification through satellite imagery was assessed in two different ways. In the first approach, a number of habitats (Fossitt level II) were categorised as being of low nature conservation value (improved grassland [GA], cultivated land $[B C]$, built land $[B L]$ and disturbed ground $[E D]$ based on degree of management, the diversity of species supported and the association with more frequent disturbance). Other habitat types were identified as being of high nature conservation value (less intensively managed habitats, habitats supporting a greater diversity of species, structural and temporal variation in the habitat but no high-disturbance management events such as ploughing). In the second approach, habitats were identified according to level III habitats (Fossitt, 2000) in order to test the methodology to identify habitats at the finest scale 
from interpretation of satellite imagery. A third approach was attempted that relied on the use of photographs to complement the interpretation of satellite imagery, and further improve the accuracy of habitat identification. Hedgerows (WL1) and treelines (WL2) were only assessed using satellite imagery (and not via ground-based survey, which was not feasible), so these were not included in the analysis.

An assessment of accuracy was achieved through the comparison of habitats as classified according to satellite imagery to evaluate how well the interpretation of images represented the habitats that were identified on the ground. When calculating the error matrix, we based calculations of error on an area basis, that is, the total area of a particular habitat based on satellite imagery was compared to the total area of ground-truthed habitat. A quantitative comparison of habitat identification methods was achieved through validation of the habitat classification. Validation was accomplished through conventional geo-statistical approaches (Congalton, 1991):

(A)

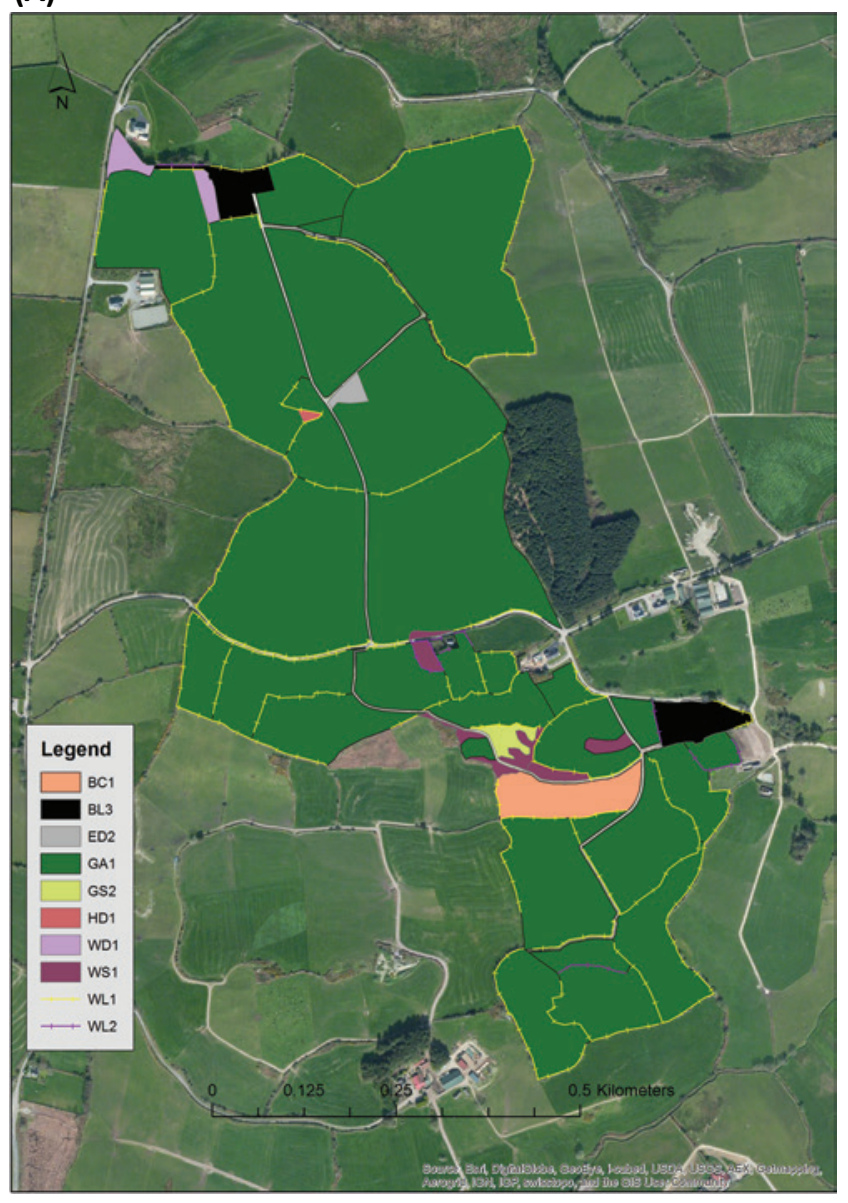

- Error matrix: a standard form reporting site-specific errors in mapping classifications, identifying overall errors and mis-classifications for each habitat category.

- Kappa ( $\mathrm{K}$ ) coefficient: a measure of the difference between the observed agreement between two maps and the agreement that might be attained solely by chance matching of two maps. It provides a measure of agreement that is adjusted for chance agreement.

- Errors of commission and omission: Errors of commission result when one incorrectly identifies pixels associated with a class (a habitat type, in this case) as other classes, or when one improperly separates a single class into two or more classes. Errors of omission occur whenever the classification does not identify the habitat that should have been identified as belonging to a particular class.

A file containing the data used to construct the confusion matrices is available on the Teagasc online repository T-Stór at https://t-stor.teagasc.ie/handle/11019/1877.

\begin{tabular}{|c|c|c|c|c|}
\hline Code & Habitat & $\begin{array}{l}\text { Area } \\
\text { (ha) }\end{array}$ & $\begin{array}{l}\text { Length } \\
\text { (m) }\end{array}$ & $\begin{array}{l}\text { Relative Wildlife } \\
\text { Importance }\end{array}$ \\
\hline $\mathrm{BC} 1$ & Arable crops & 0.99 & & $\begin{array}{l}\text { Low, but can be } \\
\text { mitigated by } \\
\text { management, and by } \\
\text { wildlife habitats in } \\
\text { adjacent areas }\end{array}$ \\
\hline BL3 & $\begin{array}{l}\text { Buildings/artificial } \\
\text { surfaces }\end{array}$ & 1.06 & & $\begin{array}{l}\text { Generally low, but old } \\
\text { farm buildings and yards } \\
\text { can benefit bats/birds }\end{array}$ \\
\hline ED2 & $\begin{array}{l}\text { Spoil and bare } \\
\text { ground }\end{array}$ & 0.13 & & $\begin{array}{l}\text { Generally low, transient } \\
\text { habitat }\end{array}$ \\
\hline GA1 & $\begin{array}{l}\text { Improved } \\
\text { agricultural } \\
\text { grassland }\end{array}$ & 42.7 & & $\begin{array}{l}\text { Low, but can be } \\
\text { mitigated by } \\
\text { management, and by } \\
\text { wildlife habitats in } \\
\text { adjacent areas }\end{array}$ \\
\hline GS2 & $\begin{array}{l}\text { Dry } \\
\text { meadows/grassy } \\
\text { verges }\end{array}$ & 0.21 & & $\begin{array}{l}\text { Medium-high. Can vary } \\
\text { considerably in quality, } \\
\text { depending on } \\
\text { management }\end{array}$ \\
\hline HD1 & Dense bracken & 0.03 & & $\begin{array}{l}\text { Medium-high, } \\
\text { management } \\
\text { dependent }\end{array}$ \\
\hline WD1 & $\begin{array}{l}\text { Mixed } \\
\text { (broadleaved) } \\
\text { woodland }\end{array}$ & 0.34 & & $\begin{array}{l}\text { Medium-high, } \\
\text { management } \\
\text { dependent }\end{array}$ \\
\hline WS1 & Scrub & 0.62 & & $\begin{array}{l}\text { Medium-high, } \\
\text { management } \\
\text { dependent }\end{array}$ \\
\hline WL1 & Hedgerow & & 6847 & $\begin{array}{l}\text { Low to very high, } \\
\text { depending on hedge } \\
\text { management. Important } \\
\text { for wildlife, and their } \\
\text { movement in landscape. }\end{array}$ \\
\hline WL2 & Treeline & & 545 & Very high \\
\hline
\end{tabular}

Figure 2. (Continued) 
(B)

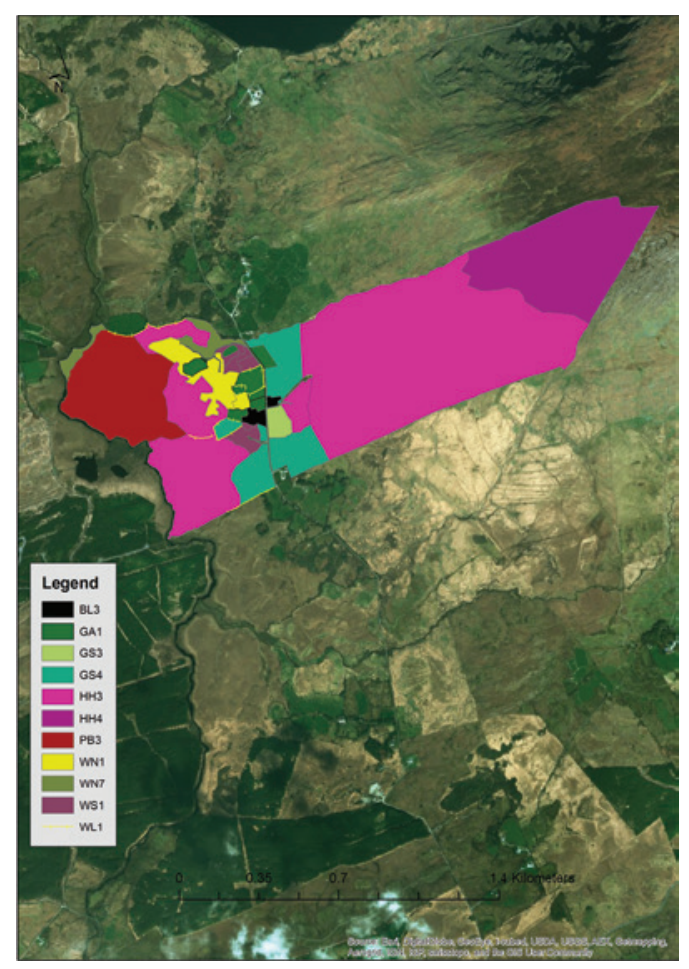

\begin{tabular}{|c|c|c|c|c|}
\hline Code & Habitat & $\begin{array}{l}\text { Area } \\
\text { (ha) }\end{array}$ & $\begin{array}{l}\text { Length } \\
\text { (m) }\end{array}$ & $\begin{array}{l}\text { Relative Wildlife } \\
\text { Importance }\end{array}$ \\
\hline BL3 & $\begin{array}{l}\text { Buildings/artificial } \\
\text { surfaces }\end{array}$ & 0.87 & & $\begin{array}{l}\text { Generally low, but old } \\
\text { farm buildings and yards } \\
\text { can benefit bats/birds }\end{array}$ \\
\hline GA1 & $\begin{array}{l}\text { Improved } \\
\text { agricultural } \\
\text { grassland }\end{array}$ & 3.50 & & $\begin{array}{l}\text { Low, but can be mitigated } \\
\text { by management, and by } \\
\text { wildlife habitats in } \\
\text { adjacent areas }\end{array}$ \\
\hline GS3 & $\begin{array}{l}\text { Dry-humid acid } \\
\text { grassland }\end{array}$ & 1.3 & & High \\
\hline GS4 & Wet grassland & 12.1 & & $\begin{array}{l}\text { Medium - high. Can vary } \\
\text { in quality, depending on } \\
\text { management. }\end{array}$ \\
\hline НH3 & Wet heath & 84.3 & & High - very high \\
\hline HH4 & Montane heath & 25.9 & & High - very high \\
\hline PB3 & $\begin{array}{l}\text { Lowland blanket } \\
\text { bog }\end{array}$ & 17.5 & & $\begin{array}{l}\text { Low - medium, } \\
\text { management- } \\
\text { dependent }\end{array}$ \\
\hline WN1 & $\begin{array}{l}\text { Oak-birch-holly } \\
\text { woodland }\end{array}$ & 4.8 & & Very high \\
\hline WN7 & Bog woodland & 2.5 & & Very high \\
\hline WS1 & Scrub & 2.6 & & $\begin{array}{l}\text { Medium-high, } \\
\text { management } \\
\text { dependent }\end{array}$ \\
\hline WL1 & Hedgerow & & 1432 & $\begin{array}{l}\text { Low to very high, } \\
\text { depending on hedge } \\
\text { management. Important } \\
\text { for wildlife, and their } \\
\text { movement in landscape }\end{array}$ \\
\hline
\end{tabular}

Figure 2. $(A)$ and $(B)$ illustrate the example of a colour-coded map and table of habitats with area/length and an indication of the relative wildlife importance of the habitats. See also Appendix 1 for an example of a complete report.

\section{Results}

A total of 187 farms, comprising an area of approximately 8,282 ha was mapped through field visits by ecologists, comprising 46 habitats classified as follows (using habitat codes from Fossitt, 2000): BC1, BC2, BC3, BC4, BL2, BL3, CM2, ED1, ED2, ED3, FL1, FL4, FL8, FS1, FW1, FW4, GA1, GA2, GM1, GS1, GS2, GS3, GS4, HD1, HH1, HH2, HH3, $\mathrm{HH} 4, \mathrm{~PB} 1, \mathrm{~PB} 2, \mathrm{~PB} 3, \mathrm{~PB} 4, \mathrm{PF} 2, \mathrm{WD} 1, \mathrm{WD2}$, WD3, WD4, WD5, WN1, WN2, WN4, WN5, WN6, WN7, WS1 and WS2). Over $90 \%$ of this area, however, comprised the following 10 habitats: improved agricultural grassland (GA1), 2,984 ha; wet heath $(\mathrm{HH} 3), 1,463$ ha; arable cropland (BC1), 992 ha; dry-humid acid grassland (GS3), 672 ha; dry siliceous heath (HH1), 415 ha; wet grassland (GS4), 335 ha; tilled land (BC3), 192 ha; upland blanket bog (PB2), 166 ha; conifer plantations (WD4), 148 ha and montane heath (HH4), 120 ha. In addition, $>760 \mathrm{~km}$ of hedgerow/treeline network was mapped based on interpretation of satellite imagery.

\section{Farm habitat reports}

We were successfully able to develop a workflow, database, file transfer protocols and reporting template to produce customised farm reports of habitats (see Figure 2, Appendix 1). These were customised to the extent that there was a farm habitat map, and generic information on habitats was only provided for the habitats identified on the farm. In presentations of the farm report to farmers and stakeholders, the inclusion of photos from each individual farm in their habitat report was considered to give a strong visual impression of a selection of farm habitats.

\section{Accuracy of habitat classification}

Habitat types (Fossitt level II) categorised as either high or low nature conservation value were successfully identified with a very high degree of accuracy using the satellite imagery.

Using the most detailed level of habitat classification (Fossitt level III) the overall accuracy of habitat interpretation from satellite imagery alone (polygon habitats), on an area basis was approximately $81 \%$, with a $\mathrm{k}$ coefficient of 0.76 . Errors of commission and omission were calculated for all habitats on an area basis and varied widely depending on the habitat type. See Table 1 for the 10 most prevalent habitats that accounted for $>90 \%$ of the area surveyed. Using habitat classes at Fossitt level III but with the heathland habitats combined, the overall accuracy of habitat interpretation from satellite imagery alone (polygon habitats), on an area basis 
Table 1: Errors of commission and omission for the 10 most prevalent habitats. These comprised $>90 \%$ of the surveyed area

\begin{tabular}{lcc}
\hline Habitat type & $\begin{array}{c}\text { Omission } \\
\text { error (\%) }\end{array}$ & $\begin{array}{c}\text { Commission } \\
\text { error (\%) }\end{array}$ \\
\hline GA1 Improved agricultural grassland & 7 & 11 \\
HH3: Wet heath & 31 & 6 \\
BC1 Arable crops & 15 & 28 \\
GS3 Dry-humid acid grassland & 1 & 8 \\
HH1 Dry siliceous heath & 9 & 0.3 \\
GS4 Wet grassland & 52 & 36 \\
BC3 Tilled land & 100 & 100 \\
PB2: Upland blanket bog & 49 & 22 \\
WD4: Conifer plantation & 11 & 24 \\
HH4: Montane heath & 0 & 76 \\
\hline
\end{tabular}

Table 2: Accuracy assessment based on area of habitat types with high versus low nature conservation value

\begin{tabular}{lcc}
\hline & $\begin{array}{c}\text { Error of } \\
\text { omission (\%) }\end{array}$ & $\begin{array}{c}\text { Error of } \\
\text { commission (\%) }\end{array}$ \\
\hline High nature conservation value & 5.32 & 2.52 \\
Low nature conservation value & 2.12 & 4.48 \\
K value & 92.75 & \\
Overall accuracy (\%) & 96.40 & \\
\hline
\end{tabular}

was approximately $86 \%$, with a $\mathrm{k}$ coefficient of 0.81 (see supplementary datafile).

Using Fossitt level II habitat classification, the overall accuracy of habitat interpretation from satellite imagery alone (polygon habitats), on an area basis was approximately $90 \%$, with a $\mathrm{K}$ coefficient of 0.86 . As above, the errors of commission and omission on an area basis varied widely depending on the habitat class (see supplementary datafile).

The overall accuracy of habitat discrimination (high vs. low nature conservation value) from satellite imagery alone (polygon habitats), on an area basis was $96.4 \%$, with a $\mathrm{k}$ coefficient of 0.93 and errors of commission and omission of approx. 5\% (Table 2).

The use of photographs to improve the accuracy of interpretation of satellite images was not conducted successfully and is not reported any further; however, lessons learned from this approach are discussed in Appendix 2.

\section{Discussion}

\section{Development of customised farm habitat reporting process}

This project piloted a methodology for the inclusion of farmland habitat information in sustainability assessments. The farm habitat report represents the end-product of several steps that included the following:

- definition of a clear spatial boundary for the area of interest (requiring farmer permission and LPIS data)

- quantification of the different areas that were occupied by different habitats

- development of a map of the farm and wildlife habitats

- indication of the relative conservation priority of the habitats

- provision of generic comments on positive wildlife features and management of the habitats.

The use of GIS, satellite imagery, and a database to collate information and produce a customised report underpinned the approach presented here, and will be essential for its scaling up to a large number of farms. This study indicates the feasibility and proof-of-application of the approach. The habitat map provides a clear spatial distribution of the habitats on the farm, the area of each and the relative wildlife importance of the different habitats. The habitat maps are provided to the farmer as part of a wider farm report that also presents several habitat photos (see Appendix 1 for an example), a table of the habitats and important wildlife and management features (Appendix 1), and a list of links for further information on farmland habitats and wildlife. If required, a farmer could provide these habitat maps for an environmental sustainability assessment as part of a sustainability certification scheme.

Looking to the future, a number of additional improvements could be made to the presentation and content of the farm habitat report. Aesthetically, the presentation could be improved or modified for specific applications. In terms of content, the relative wildlife value of the different habitats on the farm could be used to present the habitats (in a second map), as a heat map to clearly indicate those habitats likely to be of greatest conservation value, and a priority for an individual farm. The information on the (proportional) area and likely wildlife importance of each of the habitats occurring on a given farm could also be used to develop a (albeit simple) quantitative metric to reflect the quantity and quality of habitats. For the requirements of individual assurance or benchmarking processes, questionnaire responses about the state of biodiversity on the farm or wildlife-friendly management actions could be automatically added to the report (such as those of the SAI Platform; see Introduction). The report could be modified to include an interactive section with some features for farmers to add photos of wildlife on their farm, photos of wildlife habitats (see Appendix 2) and specific management actions for wildlife conservation.

\section{Satellite imagery was sufficiently accurate for habitat identification for sustainability assurance}

Overall, we conclude that this methodology based on satellite imagery is sufficiently accurate to be used for the incorporation 
of farmland habitats into sustainability assessments. Clearly, the broader the habitat grouping, the higher the overall accuracy levels, and the lower the errors in classifying individual groupings of habitats. Thus, we would advise against using Fossitt level III habitat classes, and instead use Fossitt level II classes. There may be other combinations of Fossitt level II habitat classes that would provide alternative relevant groupings with higher accuracy levels for those groupings. (See below for an example of how aggregation of heathland habitats increased overall accuracy.)

The relatively high overall accuracy values of $81-96 \%$ for the different levels of hierarchical categorisation need to be interpreted with a degree of caution. The total area surveyed is dominated by a small number of habitats that represent intensively managed land uses (see above, and Table 1), and several of the remaining wildlife habitats are represented by small areas. This imbalance in the representation of habitats is to be expected in such a sample, as various research suggests an average of about $8-12 \%$ of wildlife habitat areas in surveys of Irish farmland (excluding dedicated surveys of high nature value farmland) (e.g., Sheridan et al., 2011; Sullivan et al., 2011; Larkin et al., 2019). The overall accuracy values are therefore strongly weighted by the accuracy of the habitat classes that dominate the sampled area. The confusion matrix (see supplementary file) for the level III habitat classes shows high variation in the accuracy associated with specific habitats (and see Table 1), and several of the habitat classes represented by smaller areas have low accuracy.

The use of satellite imagery alone successfully discriminated between habitat categories grouped as either high or low nature conservation value. In practice, the habitats within the category "high nature conservation value" covered a range of habitats of widely varying quality, but they were generally grouped under this category to reflect their typical use as a habitat by wildlife. Their description as "high nature conservation value" is a relative term (in view of the management of the habitat), and more intended to reflect their higher likelihood of use by farmland wildlife in comparison to that of intensively managed and regularly disturbed areas of land. There is an element of subjectivity involved in this categorisation; for example, although most of the habitats considered to be "high nature conservation value" (in this analysis) were categorised on the basis of their vegetation composition, conifer plantations were included because smaller conifer plantations that occur on family farms can be associated with a diversity of birds and mammals that may not occur otherwise (the previous land use before the planting of the conifer plantation was not considered). Similarly, improved grassland, ploughed fields, stubble, etc., were considered to be of low nature conservation value, despite some very specific situations where these can support, for example, important populations of wild geese and swans (Matin et al., 2020).
When satellite imagery alone was used to identify individual habitat types (level III of Fossitt, 2000), there was an overall accuracy of $81 \%$, indicating that relatively good estimates of habitats and areas can be achieved using interpretation of satellite imagery alone. The limitations in accuracy were most likely due to issues such as changes in land-use due to the time lag between the recording of satellite imagery and its availability, and difficulties in identifying certain habitats from satellite imagery alone (e.g. different types of heaths). Given the high ability of the satellite imagery to discriminate between habitats of high and low nature conservation value, these data suggest that the decrease in accuracy from $96 \%$ to $81 \%$ is mostly related to "churn" within each of these two categories. This is almost inevitable as one increases the number of classes from two (the binary option of high and low nature conservation value) to $>40$. This is an important point. The accuracy level of $81 \%$ would probably not be acceptable for a survey of habitat areas that is needed for detailed quantitative scientific reporting of biodiversity. For example, there are four sub-types of heath (dry siliceous heath, $\mathrm{HH} 1$; dry calcareous heath, $\mathrm{HH} 2$; wet heath, $\mathrm{HH} 3$ and montane heath, $\mathrm{HH} 4$ ) represented in Fossitt (2000). All four sub-types can appear very similar from satellite imagery, and the primary differences in the sub-categories of heath largely depend on physical characteristics such as soil type, moisture levels and elevation. Not being able to discriminate among these heath types would be unacceptable for a scientific inventory of these internationally important habitats; for the purposes of sustainability assurance, however, categorising them as "heath" $(\mathrm{HH})$ and the ability to differentiate between, for example, GA1 and $\mathrm{HH}$, is likely to be more than acceptable (combining these within the level III analysis increased the overall accuracy from $81 \%$ to $86 \%$ ). As one counterexample, the aggregation of BL1 (stone walls and other stone works), BL2 (earth banks) and BL3 (buildings and artificial surfaces) would combine wildlife habitats (BL1 and BL2) with a land use (BL3) that is typically of low nature conservation value and confound the interpretation of the BL class.

A number of sources of error can contribute to reducing the overall accuracy. The time lag between capture and availability of satellite imagery is a potential source of error in the utilisation of satellite imagery to identify habitats. In this study, 2013 imagery was used in 2016; thus, for example, fields may have changed from grassland to arable to tilled land as part of a crop rotation or areas of woodland may have been cut down or established since the satellite image was recorded. This is unavoidable if there is a time lag in the provision of imagery. The time of year at which imagery was captured can also influence interpretation. For example, if satellite imagery was captured in mid-summer, but a field visit carried out in autumn, arable crops (BC1) as identified 
from the satellite imagery are likely to be classified as tilled land (BC3) in a post-harvest visit when ploughing has recently occurred. Another potential source of error is the repeatability of habitat assessment across different ecologists conducting either the assessment of the satellite imagery or the fieldwork. This was likely to be minimised in this study which had a team of ecologists with a history of working together; however, it would be expected to increase as the number of farms and assessors would increase. In practice, the use of practice guides and training can help to reduce this source of error.

\section{To what degree can this approach contribute to the assessment of farmland wildlife habitats?}

Many sustainability assessments in the agri-food system struggle to include biodiversity, and certainly struggle to do so across large numbers of farms; as a consequence, biodiversity can be omitted or treated in a superficial manner. Thus, the use of satellite imagery offers strong potential to increase the inclusion of farmland wildlife habitats in assessments of agricultural sustainability. Clearly, confirmation of the specific type of wildlife habitat (Fossitt level III) is more problematic for some habitats than others (but see below for potential solutions); nevertheless, this approach can still be reliably used to identify areas as a broad category of wildlife habitat. We consider it a distinct improvement to implement a methodology that can provide broadly correct information on wildlife habitats, in comparison to having no information at all. Through comparison of habitat maps over time, a clear contribution of this approach is the ability to confirm, and provide farmers credit for, the persistence of wildlife habitat areas on their farm. The examples provided clearly show the potential of the method to identify differences (at least) in habitat distributions among different types of farmland (compare Figure 2A, 2B and Appendix 1).

Our approach does not reflect the occurrence of a wide representation of species that would indicate biodiversity in more detail. Our approach only classifies habitats according to the categories in Fossitt (2000), and in no way reflects the quality of the habitats or reflects the occurrence of species of high conservation value. Looking to the future, however, improved incorporation of existing biodiversity information (from the National Parks and Wildlife Service, or biodiversity records) could improve knowledge of the habitats and species that occur nearby or on an individual farm. Another potential solution is for the provision of habitat and species' photos by farmers for improved identification of habitats and species (photos are currently used for other purposes in farm quality assurance schemes). This could allow more accurate assessment of habitat type and quality (by an ecologist who need never visit the farm), and may be related to highertier certification standards for farms that demonstrate their attainment of high levels of biodiversity provision.
One specific limitation observed when identifying Fossitt level III habitats from satellite imagery alone is the inability to observe drainage ditches, streams and even larger watercourses that are associated with hedgerows/treelines, because their presence is masked by the canopy. This limitation might be overcome through the use of Ordnance Survey Ireland (OSI) water polygon data, but only if it was of sufficient resolution. More generally, the accuracy of using satellite interpretation to identify habitats could be greatly enhanced with the provision of additional data. These data primarily relate to altitude, soil type, slope, etc. Relevant additional data could also indicate the spatial location of wildlife habitats across larger spatial scales that encompass multiple farms. Such additional data would help to identify and include natural, protected and priority habitats (both terrestrial and aquatic). The additional data should also include species of high conservation interest (Walsh et al., 2015), for example, threatened, endangered and protected species (including migratory wildlife). These data are typically available from national wildlife agencies.

\section{Lessons learned and future directions}

This study demonstrates proof-of-application of a methodology to identify farmland habitats that reduces the logistical effort associated with farm-by-farm field surveys. We conclude that satellite imagery can be used with sufficient reliability to identify broad habitats for the purposes of conducting farm habitat assessments for sustainability certification. In addition, the use of satellite imagery can be part of an automated process for reporting across large numbers of farms. Compared to individual site visits, the most cost- and time-efficient means of mapping habitats for individual farms was through the interpretation of satellite imagery, as this incurred none of the costs associated with site visits (such as mileage, subsistence and additional time for labour that is incurred by travelling, as well for the actual time spent conducting the survey). The approach presented here still requires an ecologist to view, interpret and record the habitat types from the satellite imagery for each individual farm. Looking to the future, remote sensing technology offers a promising opportunity to further automate and upscale the identification of habitats (Lucas et al., 2007; Corbane et al., 2015; Cruzan et al., 2016).

Regardless of whether the interpretation of imagery is conducted by an ecologist or computer software (via remote sensing technology or machine learning), some significant logistical challenges need to be overcome. In this study, the need to identify the farm boundaries was dependent on access to LPIS data from the Department of Agriculture, Food and the Marine (DAFM). This requires the permission of a farmer to use their herd number and LPIS data. (Note that Teagasc had privileged access to LPIS data, which expedited completion of this task.) This study relied on voluntary participation by farmers, and there were delays in acquiring permissions to 
use the farmer's herd number and LPIS data, even when this only required an SMS response. Until permissions and LPIS data were provided for a farm, no work could be conducted in relation to that farm. Within the LPIS data, some inaccuracies were encountered, most notably with the alignment between LPIS data and the 1:5,000 OSI data. In addition, LPIS data was found on several occasions to be out-of-date (parcels had changed ownership) and, in a small number of cases, in error as regards ownership. Although the majority of farms were located within a reasonably compact area, some farms contained parcels that were separated by 10 s of kilometres that presented obvious logistical difficulties when aiming to visit such parcels. With some parcels separated by large distances, it was sometimes necessary to produce more than one map per farm to maintain sufficient magnification for the different land parcels to be visible.

Our approach focuses on the scale of an individual farm, and does not include off-farm impacts on biodiversity. If such habitat reports are to be used to guide farm-scale actions for wildlife conservation (rather than survey and record what is present), then decision-making on actions should be within the context of broader strategic planning for biodiversity priorities at the landscape scale. Off-farm impacts should be a priority for future work as off-farm impacts can represent a substantial proportion of the total impact on biodiversity of a farming system (e.g. see Teillard et al., 2016; Lynch et al., 2019). Habitat degradation associated with feed production can occur in locations far from the place of consumption, causing significant impacts on local and regional biodiversity (Lenzen et al., 2012), for example, the removal of tropical rainforest for the cultivation of crops to be transported for animal feed. Future iterations of our approach could improve the integration of off-farm impacts by linking to available information on the farm's temporal increase or decrease in the reliance on off-farm feed production, and by improving knowledge of the geographical location of the source of offfarm feed (LEAP, 2016).

Brand reputation of agri-food products can be especially sensitive to wildlife issues (both positively and negatively), so the ability to incorporate a measure of farmland biodiversity (habitat coverage, in this case) will be essential to adequately satisfy modern assessments of agricultural sustainability. The approach presented here offers a methodology to incorporate wildlife habitats into sustainability assurance processes. The capacity to conduct an assessment, however, brings with it an increased focus on the standards and norms that should be expected of food production systems (this is the intention of such assessments). For example, for the biodiversity dimension of sustainability, what threshold level represents that level below which an assessment would: fail?; not fail but require improvement?; be sufficient to not require any further improvement?; be recognised for providing exceptional levels of farmland biodiversity? The credibility of claims about sustainability is extremely important, and such issues will need to be addressed in a way that satisfies multiple stakeholders.

\section{Data availability}

A file containing the data used to construct the confusion matrices is available on the Teagasc online repository T-Stór at https://t-stor.teagasc.ie/handle/11019/1877.

\section{Acknowledgements}

We thank all of the participating farmers for permission to access their farms and farm data. We thank Padraig Brennan of Bord Bia for discussion that contributed to the conceptual development of the project. Both Padraig Brennan and Eamon Joyce of Bord Bia facilitated the selection of most of the farmers who participated in the project. We acknowledge Bord Bia's funding of the work of Tim Mackey (CodePlus) in developing an app for farm photos, and implementing the automated reporting process. We thank Stuart Green for assistance with provision of GIS data.

\section{References}

Addison, P.F.E., Bull, J.W. and Milner-Gulland, E.J. 2018. Using conservation science to advance corporate biodiversity accountability. Conservation Biology 33: 307-318.

Barbier, E.B., Burgess, J.C. and Dean, T.J. 2018. How to pay for saving biodiversity. Science 360: 486-488.

Boiral, O. 2016. Accounting for the unaccountable: biodiversity reporting and impression management. Journal of Business Ethics 135: 751-768.

Congalton, R.G. 1991. A review of assessing the accuracy of classifications of remotely sensed data. Remote Sensing of Environment 37: 35-46.

Corbane, C., Lang, S., Pipkins, K., Alleaume, S., Deshayes, M., Millán, V.E.G., Strasser, T., Borre, J.V., Toon, S. and Michael, F. 2015. Remote sensing for mapping natural habitats and their conservation status - new opportunities and challenges. International Journal of Applied Earth Observation and Geoinformation 37: 7-16.

Cruzan, M.B., Weinstein, B.G., Grasty, M.R., Kohrn, B.F., Hendrickson, E.C., Arredondo, T.M. and Thompson, P.G. 2016. Small unmanned aerial vehicles (micro-UAVs, drones) in plant ecology. Applications in Plant Sciences 4: 1600041. Available online: https://doi.org/10.3732/apps.1600041.

Dempsey, J. 2013. Biodiversity loss as material risk: tracking the changing meanings and materialities of biodiversity conservation. Geoforum 45: 41-51. 
Fossitt, J. 2000. "A Guideline to Habitats in Ireland". The Heritage Council, Kilkenny, Ireland.

Hayati, D. 2017. A literature review on frameworks and methods for measuring and monitoring sustainable agriculture. Technical Report No. 22, Global Strategy Technical Report, Rome, Italy. Available online: http://www.fao.org/3/a-br906e.pdf.

Larkin, J., Sheridan, H., Finn, J.A., Denniston, H. and Ó hUallacháin, D. 2019. Semi-natural habitats and ecological focus areas on cereal, beef and dairy farms in Ireland. Land Use Policy 88: 104096.

LEAP. 2016. "Principles for the Assessment of Livestock Impacts on Biodiversity". Version 1. Livestock Environmental Assessment and Performance Partnership. FAO, Rome, Italy. Available online: http://www.fao.org/3/a-i6492e.pdf [Accessed 9 October 2019].

Lenzen, M., Moran, D., Kanemoto, K., Foran, B., Lobefaro, L. and Geschke, A. 2012. International trade drives biodiversity threats in developing nations. Nature 486: 109-112.

Lucas, R., Rowlands, A., Brown, A., Keyworth, S. and Bunting, P. 2007. Rule-based classification of multi-temporal satellite imagery for habitat and agricultural land cover mapping. ISPRS Journal of Photogrammetry and Remote Sensing 62: 165-185.

Lynch, J., Donnellan, T., Finn, J.A., Dillon, E. and Ryan, M. 2019. Potential development of Irish agricultural sustainability indicators for current and future policy evaluation needs. Journal of Environmental Management 230: 434-445.

Matin, S., Sullivan, C.A., Ó hUallacháin, D., Meredith, D., Moran, J., Finn, J.A. and Green, S. 2016. Predicted distribution of High Nature Value farmland in the Republic of Ireland. Journal of Maps 12(Sup 1): 373-376. Available online: http://www.tandfonline.com/ doi/abs/10.1080/17445647.2016.1223761.

Matin, S., Sullivan, C.A., Finn, J.A., Ó hUallacháin, D., Green, S., Meredith, D. and Moran, J. 2020. Assessing the distribution and extent of high nature value farmland in the Republic of Ireland. Ecological Indicators 108: 107500.

Parguel, B., Benoît-Moreau, F. and Larceneux, F. 2011. How sustainability ratings might deter 'greenwashing': a closer look at ethical corporate communication. Journal of Business Ethics 102: 15-28.

Sheridan, H., McMahon, B.J., Carnus, T., Finn, J.A., Kinsella, A. and Purvis, G. 2011. Pastoral farmland habitat diversity in southeast Ireland. Agriculture, Ecosystems \& Environment 144: 130-135.

Sullivan, C.A., Bourke, D., Gormally, M.J., Sheehy Skeffington, M., Finn, J.A., Green, S. and Kelly, S. 2011. Modelling semi-natural habitat area on lowland farms in western Ireland. Biological Conservation 144: 1089-1099.

Smith, G.F., O'Donoghue, P., O'Hora, K. and Delaney, E. 2011. "Best Practice Guidance for Habitat Survey and Mapping". The Heritage Council, Kilkenny, Ireland.

Teillard, F., Maia de Souza, D., Thoma, G., Gerber, P.J. and Finn, J.A. 2016. What does Life-Cycle Assessment of agricultural products need for more meaningful inclusion of biodiversity? Journal of Applied Ecology 53: 1422-1429.

Treves, A. and Jones, S.M. 2010. Strategic tradeoffs for wildlifefriendly eco-labels. Frontiers in Ecology and the Environment 8: 491-498.

United Nations. 2018. "Sustainable Development Goals". Available online: http://www.un.org/sustainabledevelopment/ [Accessed 18 September 2018].

Walsh, A., Finn, J., Jebb, M., Waldren, S. and Sullivan, C. 2015. The distribution of vascular plant species of conservation concern in Ireland, and their coincidence with designated areas. Journal for Nature Conservation 24: 56-62. 


\section{Appendix 1}

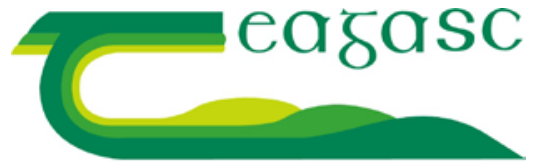

Produced as part of a Teagasc-funded project on habitat surveys of Irish farmland, and in collaboration with Bord Bia. Disclaimer: The area calculations and indicated boundaries of this farm habitat map are for guidance only.

Bord Bla

Irish Food Board

Agriculture and Food Development Authortty

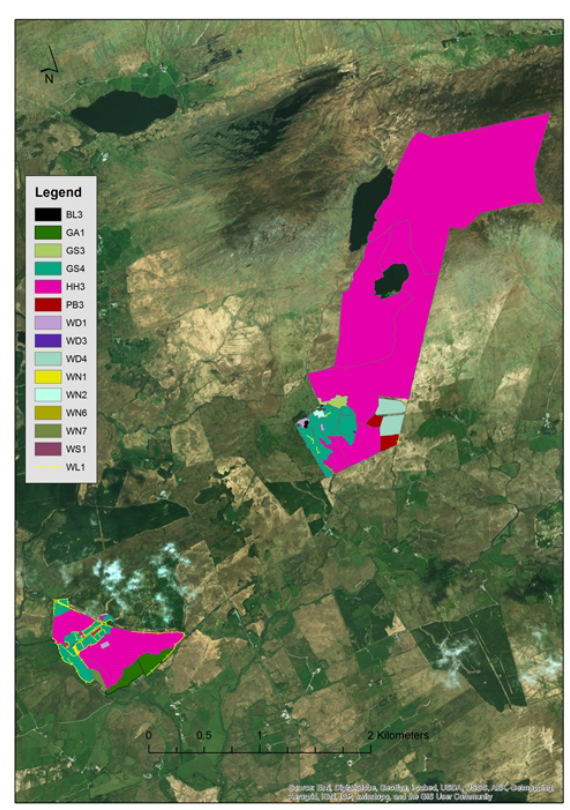

\begin{tabular}{|c|c|c|c|c|}
\hline Code & Habitat & $\begin{array}{l}\text { Area } \\
\text { (ha) }\end{array}$ & $\begin{array}{l}\text { Length } \\
\text { (m) }\end{array}$ & $\begin{array}{l}\text { Relative Wildlife } \\
\text { Importance }\end{array}$ \\
\hline BL3 & $\begin{array}{l}\text { Buildings / } \\
\text { artificial surfaces }\end{array}$ & 0.26 & & $\begin{array}{l}\text { Generally low, but old farm buildings } \\
\text { and yards can benefit bats/birds }\end{array}$ \\
\hline GA1 & $\begin{array}{l}\text { Improved } \\
\text { agricultural } \\
\text { grassland }\end{array}$ & 7.18 & & $\begin{array}{l}\text { Low, but can be mitigated by } \\
\text { management, and by wildlife } \\
\text { habitats in adjacent areas }\end{array}$ \\
\hline GS3 & $\begin{array}{l}\text { Dry-humid acid } \\
\text { grassland }\end{array}$ & 1.86 & & High \\
\hline GS4 & Wet grassland & 26.59 & & $\begin{array}{l}\text { Medium - high. Can vary in quality, } \\
\text { depending on management. }\end{array}$ \\
\hline Нн3 & Wet heath & 269.48 & & High-very high \\
\hline PB3 & $\begin{array}{l}\text { Lowland blanket } \\
\text { bog }\end{array}$ & 3.18 & & $\begin{array}{l}\text { Low-medium, management } \\
\text { dependent }\end{array}$ \\
\hline WD1 & $\begin{array}{l}\text { Mixed } \\
\text { (broadleaved)wo } \\
\text { odland }\end{array}$ & 0.96 & & $\begin{array}{l}\text { Medium-high, management } \\
\text { dependent }\end{array}$ \\
\hline WD3 & $\begin{array}{l}\text { Mixed (conifer) } \\
\text { woodland }\end{array}$ & 0.13 & & Medium \\
\hline WD4 & $\begin{array}{l}\text { Conifer } \\
\text { plantation }\end{array}$ & 6.62 & & Low to medium \\
\hline WN1 & $\begin{array}{l}\text { Oak-birch-holly } \\
\text { woodland }\end{array}$ & 0.26 & & Very high \\
\hline
\end{tabular}

\section{SELECTED PHOTOS OF HABITATS}
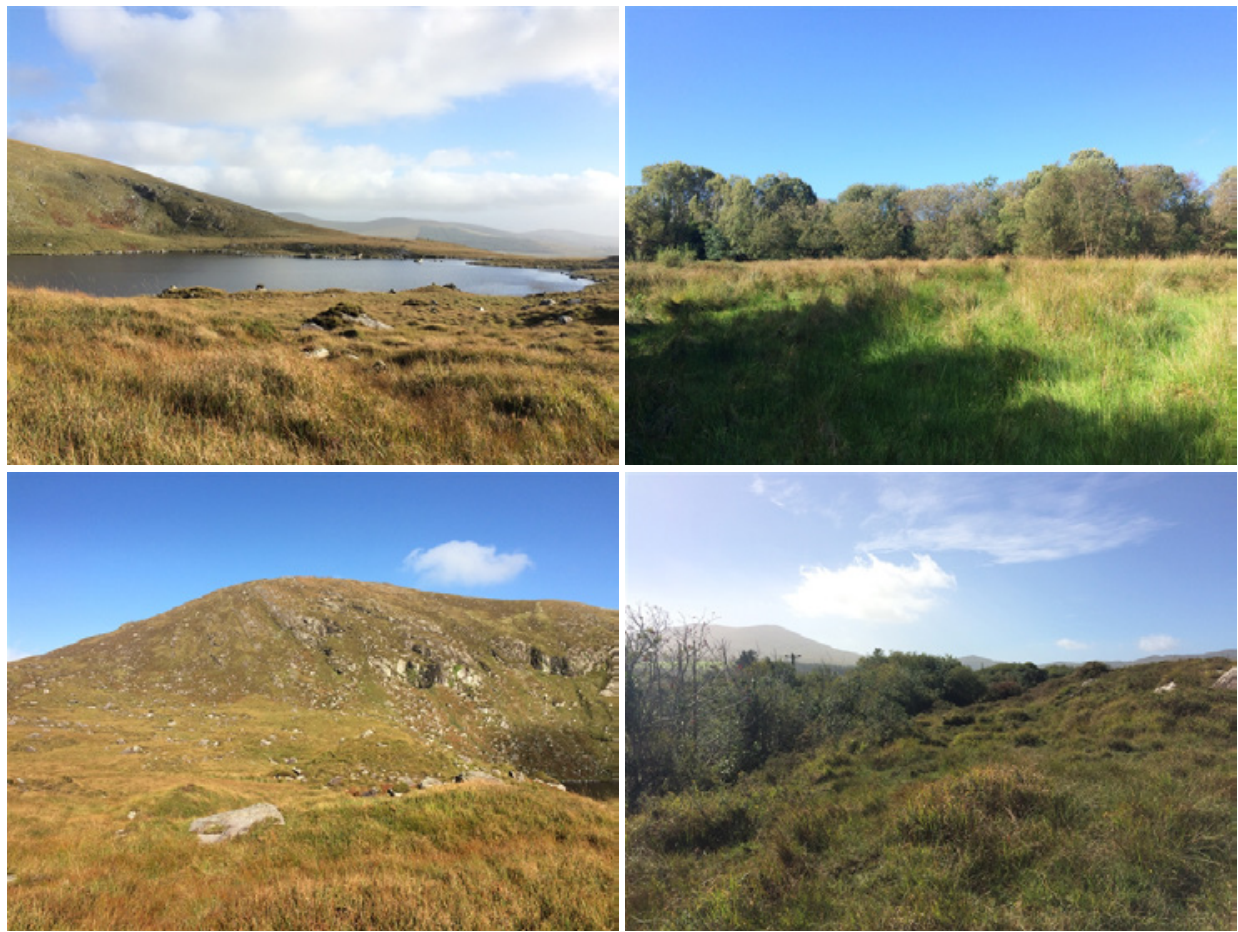


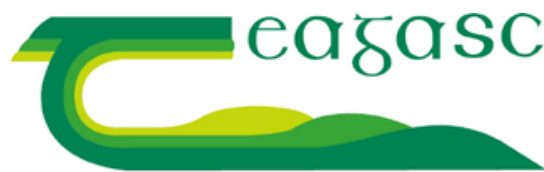

Agriculture and Food Development Authority
Produced as part of a Teagasc-funded project on habitat surveys of Irish farmland, and in collaboration with Bord Bia. Disclaimer: The area calculations and indicated boundaries of this farm habitat map are for guidance only.

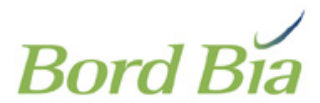

Irish Food Board

General advice for wildlife habitats

- Designated sites (such as SACs, SPAs, NHAs) will have management plans and recommendations that should be followed, and take priority over information here.

- The priority should be to retain existing habitats that contain local species. In general, the wildlife value of farmland habitats will be greater in older areas.

- If new habitats are created, they should not be located on existing wildlife habitats.

- Carefully manage the input of agri-chemicals (e.g. nutrients from fertilisers, slurry and manure; herbicides, pesticides and rodenticides). Many farmland habitats are dependent on farming practice. Continue traditional farming practices on wildlife habitats, which avoid overgrazing, undergrazing and excess application of nutrients.

\begin{tabular}{|c|c|}
\hline $\begin{array}{l}\text { Habitat } \\
\text { Code }\end{array}$ & $\begin{array}{l}\text { Management Tips to Maintain/Enhance Ecological Value Of Habitats - } \\
\text { See Detailed Management Measures Document }\end{array}$ \\
\hline BL3 & $\begin{array}{l}\text { BUILDINGSIARTIFICIAL SURFACES } \\
\text { These can be managed to increase wildlife value - erect bat/bird boxes, reduce rodenticide use around the farm, dispose of unneeded } \\
\text { chemicals responsibly. Even small patches of wild vegetation can support pollinators and birds. Old farm buildings are ideal habitats for } \\
\text { bats. }\end{array}$ \\
\hline GA1 & $\begin{array}{l}\text { IMPROVED AGRICULTURAL GRASSLAND } \\
\text { A number of actions can reduce wildlife impacts. Implement nutrient management plans and prevent nutrient transfer to waterways to } \\
\text { protect aquatic wildlife. Hedgerows and buffer strips with native grasses and wildflowers along the field margins can greatly enhance } \\
\text { the wildlife value of this habitat. Insects, birds, bats and other mammals will use the undisturbed areas for feeding, breeding and } \\
\text { movement in the landscape. If used for silage/hay, time cuts to minimise impacts on ground-nesting birds. }\end{array}$ \\
\hline GS3 & $\begin{array}{l}\text { DRY-HUMID ACID GRASSLAND } \\
\text { This habitat is of high ecological importance - management measures should be maintained at current levels. }\end{array}$ \\
\hline GS4 & $\begin{array}{l}\text { WET GRASSLAND } \\
\text { This habitat is of high ecological importance - management measures should be maintained at current levels. }\end{array}$ \\
\hline HH3 & $\begin{array}{l}\text { WET HEATH } \\
\text { This habitat is of high ecological importance - management measures should be maintained at current levels. }\end{array}$ \\
\hline PB3 & $\begin{array}{l}\text { LOWLAND BLANKET BOG } \\
\text { This habitat is of high ecological importance - management measures should be maintained at current levels. }\end{array}$ \\
\hline WD1 & $\begin{array}{l}\text { MIXED (BROADLEAVED)WOODLAND } \\
\text { Ecological value can be greatly improved by increasing number of native species and enhancing structural diversity. }\end{array}$ \\
\hline WD3 & $\begin{array}{l}\text { MIXED (CONIFER) WOODLAND } \\
\text { Can be of ecological importance for species such as pine marten and red squirrel - if clear-felling do so in phases. }\end{array}$ \\
\hline WD4 & $\begin{array}{l}\text { CONIFER PLANTATION } \\
\text { Can be of ecological importance for species such as hen harrier, pine marten and red squirrel - if clear-felling, do so in phases. }\end{array}$ \\
\hline WN1 & $\begin{array}{l}\text { OAK-BIRCH-HOLLY WOODLAND } \\
\text { This habitat is of very high ecological importance - management measures should be maintained at current levels. }\end{array}$ \\
\hline WN2 & $\begin{array}{l}\text { OAK-ASH-HAZEL WOODLAND } \\
\text { This habitat is of very high ecological importance - management measures should be maintained at current levels. }\end{array}$ \\
\hline WN6 & $\begin{array}{l}\text { WET WILLOW-ALDER-ASH WOODLAND } \\
\text { This habitat is of very high ecological importance - management measures should be maintained at current levels }\end{array}$ \\
\hline
\end{tabular}




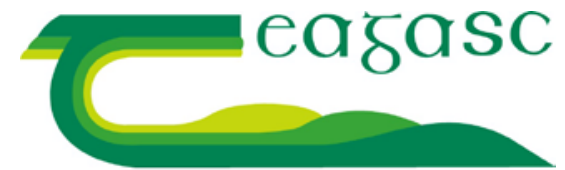

Produced as part of a Teagasc-funded project on habitat surveys of Irish farmland, and in collaboration with Bord Bia. Disclaimer: The area calculations and indicated boundaries of this farm habitat map are for guidance only.

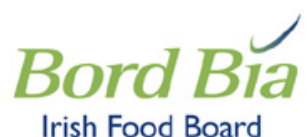

Irish Food Board

Agriculture and Food Development Authority

\section{WN7}

WS1

WL1
BOG WOODLAND

This habitat is of very high ecological importance - management measures should be maintained at current levels.

\section{SCRUB}

Scrub can support a high diversity of wildlife on farms that have very little other farmland wildlife habitat. It usually has a modest number of plant species, but provides feeding and nesting opportunities of particular importance for farmland birds in addition to the structural diversity required by many insects.

HEDGEROW

Their widespread occurrence in many Irish landscapes makes hedgerows an important wildlife habitat. Their wildlife value varies, but is greater in older, wider and taller hedgerows with a dense base and some mature trees. Hedgerows provide food, shelter, corridors of movement, breeding and hibernation sites for many native plants and animals. Management must not occur during the bird-nesting season from March to August.

\section{Further information on farmland wildlife habitats:}

- The National Biodiversity Data Centre www.biodiversityireland.ie

- The Heritage Council. Booklet on Farmland habitats www.heritagecouncil.ie/content/files/farmland_habitats_series_01_2007_1mb.pdf

- Teagasc webpages on farmland habitats www.teagasc.ie/environment/biodiversity--countryside/farmland-habitats

- All-Ireland Pollinator Plan $\underline{\text { www.biodiversityireland.ie/projects/irish-pollinator-initiative/all-ireland-pollinator-plan }}$ 


\section{Appendix 2}

\section{Use of photography to improve habitat identification}

An additional task in the project aimed to investigate the feasibility of using photographs of farm habitats to improve the accuracy of habitat identification. It was expected that the provision of photographs of selected habitats in addition to satellite imagery would greatly enhance the ability of an ecologist to identify habitats to Fossitt level III. The intention was that a small group of advisors known to be visiting the farms would be requested to use a phone-based application (app) to take photos of selected habitats. The phone application was developed to be able to implement the following process. The process was intended to be as follows:

- An ecologist would remotely identify farm habitats (using satellite imagery alone)

- Any habitats that were difficult to classify would be marked on a geospatial map of the farm

- An advisor visiting the farm would use the app to view the map of the farm, and take photos of the marked habitat at the locations indicated on the map

- The app would geocode the photos (thereby linking the farm and habitat to the photo) and upload the photos to the database

- The ecologist could remotely view the photo and be better informed of the habitat type

The above method successfully demonstrated proof-ofprinciple (the workflow described was achieved in several cases); however, it did not demonstrate proof-of-practice. This was due to limitations associated with the provision of requested photographs, primarily: relatively low return of selected photos; photos taken in the wrong location or of the wrong habitat, and; return of photos with poor quality. These limitations largely derived from the logistical constraints on the farm visits by advisors. The taking of photos was a "bolt-on" activity to a scheduled visit. Logistical constraints included: weather conditions on the scheduled date frequently prevented good quality photos being achieved; weather conditions resulted in photos of more inaccessible locations being taken from too far a distance, and; the fragmentation of farms meant that remote farm parcels were not visited during the scheduled visit.

Looking to the future, the limitations associated with provision of photographs can be easily overcome. If images are supplied as requested, the overall accuracy of identification of Fossitt Level III habitats and associated $\mathrm{k}$ values could certainly be enhanced. In addition, such photos could be used as examples of the farm habitats to be included in the farm report, and could also be used to provide an indication of habitat quality (if taken in a format that would represent a "photographic quadrat").

Looking to the future, there is considerable merit in requesting farmers to take the photographs, as they have the best knowledge of their farm holding and habitats, and the motivation to capture photographs in the appropriate location and when the habitats appear at their best (e.g. in flower before mowing or grazing, on a sunny day). In addition, farmers could easily take photos of marked habitats located in farm fragments (over time). The app used by the farmer to capture photographs should have a guidance system, whereby the app will only allow the farmer to take a photograph when they are within 5-10 m of the requested location. Farmers within Bord Bia's Quality Assurance and Sustainability Schemes currently use photos to confirm changes and compliance, so this is not an unprecedented request. There may also be the possibility of using drone technology as part of farm visits (Cruzan et al., 2016), although this would require increased logistical effort and would also be subject to weather constraints. 